\title{
PR72, a novel regulator of Wnt signaling required for Naked cuticle function
}

\author{
Menno P. Creyghton, ${ }^{1,3}$ Giulietta Roël, ${ }^{2,3}$ Pieter J.A. Eichhorn, ${ }^{1}$ E. Marielle Hijmans, ${ }^{1}$ Irma Maurer, ${ }^{1}$ \\ Olivier Destrée, ${ }^{2}$ and René Bernards ${ }^{1,4}$ \\ ${ }^{1}$ Division of Molecular Carcinogenesis and Center for Biomedical Genetics, The Netherlands Cancer Institute, 1066 CX \\ Amsterdam, The Netherlands; ${ }^{2}$ Netherlands Institute for Developmental Biology (NIOB), Hubrecht Laboratory, 3584 CT \\ Utrecht, The Netherlands
}

The Wnt signaling cascade is a central regulator of cell fate determination during embryonic development, whose deregulation contributes to oncogenesis. Naked cuticle is the first Wnt-induced antagonist found in this pathway, establishing a negative-feedback loop that limits the Wnt signal required for early segmentation. In addition, Naked cuticle is proposed to function as a switch, acting to restrict classical Wnt signaling and to activate a second Wnt signaling pathway that controls planar cell polarity during gastrulation movements in vertebrates. Little is known about the biochemical function of Naked cuticle or its regulation. Here we report that PR72, a Protein Phosphatase type 2A regulatory subunit of unknown function, interacts both physically and functionally with Naked cuticle. We show that PR72, like Naked cuticle, acts as a negative regulator of the classical Wnt signaling cascade, establishing PR72 as a novel regulator of the Wnt signaling pathway. Our data provide evidence that the inhibitory effect of Naked cuticle on Wnt signaling depends on the presence of PR72, both in mammalian cell culture and in Xenopus embryos. Moreover, PR72 is required during early embryonic development to regulate cell morphogenetic movements during body axis formation.

[Keywords: PR72; Naked cuticle; Wnt signaling; Xenopus tropicalis]

Received May 16, 2004; revised version accepted November 24, 2004.

Mammalian development is critically dependent on several fine-tuned and conserved signaling cascades. Hedgehog, TGF- $\beta$, EGF, FGF, and Wnt signals interlace to specify patterned changes in gene expression, cell fate, and tissue polarity to ensure the diverse developmental steps needed to compose a complex body plan (Moon and Kimelman 1998; Niehrs 1999; Bouwmeester 2001; Keller 2002; Agathon et al. 2003; Aulehla et al. 2003). Perhaps not surprisingly, aberrant regulation of these signaling cascades leads to diverse developmental defects in the early embryo and can contribute to oncogenesis (Polakis 2000; Giles et al. 2003). Therefore, tight regulation of these signaling cascades is a prerequisite. This is accomplished not only by the many cross-regulatory signals but also by several negative-feedback loops (Perrimon and McMahon 1999). During canonical Wnt signaling, Wnt-induced stimulation of the seven-pass transmembrane frizzled receptors and members of the low-density lipoprotein receptor-related protein family (LRP) leads to an increase in stable cytoplasmic $\beta$-catenin levels. This is followed by nuclear translocation of $\beta$-catenin and dimerization with the TCF/Lef-1 transcription factors

\footnotetext{
${ }^{3}$ These authors contributed equally to this work. ${ }^{4}$ Corresponding author.

E-MAIL Bernards@nki.nl; FAX 31-20-512-1954.

Article and publication are at http://www.genesdev.org/cgi/doi/10.1101/ gad.328905.
}

(for review, see Cadigan and Nusse 1997), leading to the transcription of Wnt target genes (Brunner et al. 1997; van de Wetering et al. 1997). The stabilization of $\beta$-catenin requires the inactivation of the Axin/APC/ GSK3 $\beta$ destruction complex. In the absence of the Wnt signal this complex stimulates GSK3 $\beta$-mediated phosphorylation of $\beta$-catenin (Yost et al. 1996; Ikeda et al. 1998), targeting it for proteasomal degradation (Aberle et al. 1997).

Upon Wnt ligand binding to its receptor, the subsequent inactivation of the Axin/APC/GSK3 $\beta$ destruction complex needs an upstream component named dishevelled (Dsh) to inhibit GSK3 $\beta$ activity (Klingensmith et al. 1994; Theisen et al. 1994) and LRP for Axin destabilization (Mao et al. 2001). How dishevelled is activated by Wnt ligands is unclear, but it is possible that its inhibition of the destruction complex is mediated through disruption of Axin dimers required for the CK1/GSK3 $\beta$-mediated phosphorylation of $\beta$-catenin (Kishida et al. 1999).

One of the target genes of the Wnt signaling cascade is Naked cuticle ( $N k d)$, whose activity is required to restrict Wnt signaling during Drosophila embryonic segmentation, thus generating a negative-feedback loop. Naked cuticle was the first Wnt antagonist found to be induced by the Wnt pathway (Zeng et al. 2000) followed by Axin2 (Jho et al. 2002; Lustig et al. 2002) and Tak1 (Smit et al. 2004). Overexpression of $N k d$ mRNA in Xenopus embryos results in severe truncation of the an- 
terior-posterior body axis, which is similar to phenotypes observed for overexpression of known Wnt inhibitors. In line with this, the induction of a secondary body axis in Xenopus embryos induced by ectopic Wnt signaling can be blocked by coinjection of $N k d$ mRNA (Zeng et al. 2000).

A second Wnt signaling cascade diverges at the level of dishevelled from the canonical ( $\beta$-catenin-dependent) Wnt signaling cascade to specify asymmetric cell polarity and tissue organization (for review, see Shulman et al. 1998). This planar cell polarity (PCP) pathway depends on the dishevelled-mediated activation of JNK kinase (Boutros et al. 1998), which involves relocalization of dishevelled to the plasma membrane (Axelrod et al. 1998) and activation of the Rac, and Rho GTPases (Habas et al. 2003). In contrast to generating a negative-feedback loop in the classical Wnt signaling cascade, it was suggested that Nkd misexpression positively influences the PCP pathway (Yan et al. 2001a). Consistent with this, Nkd interacts with dishevelled (Rousset et al. 2001; Yan et al. 2001a) and is therefore located at the branchpoint where the classical and PCP pathways diverge (Boutros and Mlodzik 1999). In contrast to these findings, Naked was also found to mimic loss-of-function dishevelled (Rousset et al. 2001), raising the possibility that ectopic Naked sequesters dishevelled into an inactive complex. This finding is substantiated by the fact that Naked mutant flies have no apparent defect in wing cell polarity (Zeng et al. 2000).

A third signaling pathway under the control of Wnt ligands is the less well-defined $\mathrm{Wnt} / \mathrm{Ca}^{2+}$ pathway (Miller et al. 1999a; Kuhl et al. 2000). Here Wnt-activated frizzled receptors control the release of $\mathrm{Ca}^{2+}$, thereby regulating $\mathrm{Ca}^{2+}$-sensitive enzymes such as $\mathrm{Ca}^{2+}$ calmodulin dependent kinase (CamKII) and protein kinase $\mathrm{C}(\mathrm{PKC})$. This pathway also requires dishevelled as a key regulator (Sheldahl et al. 2003). Naked cuticle contains two recognizable domains of interest, a calciumbinding EF-hand (EFX) domain and a zinc-binding domain. These were found to contribute to Nkd function and dishevelled binding in vitro and in vivo (Wharton et al. 2001; Rousset et al. 2002). Apart from these observations, the biochemical function of $\mathrm{Nkd}$, as well as any possible upstream regulation, remains illusive.

Understanding the precise regulation of the Wnt regulatory feedback mechanism is essential to understanding the role of this pathway in embryonic development and its aberrant activation leading to a diverse spectrum of human cancers (Polakis 2000; Giles et al. 2003). Here we show an unexpected role for PR72 (Hendrix et al. 1993; Janssens et al. 2003), an EFX domain-containing regulatory subunit of Protein Phosphatase 2A (PP2A), in the regulation of the Wnt signaling cascade through its interaction with Naked cuticle.

\section{Results}

\section{PR72 interacts with Naked cuticle}

PP2A is a multifunctional phosphatase holoenzyme involved in numerous cellular processes (for review, see
Schonthal 1998; Millward et al. 1999|. Multiple families of PP2A regulatory B-subunits confer substrate specificity to the PP2Ac (catalytic)/PR65 (structural) core phosphatase complex by mediating interactions with specific substrates. One such regulatory B-subunit of unknown function is PR72 (Hendrix et al. 1993). To begin to characterize the function of this subunit, we performed a yeast two-hybrid screen using human PR72 as bait. Only one interacting protein was identified, which after DNAsequence analysis was found to encode the mouse ortholog of Drosophila Naked cuticle (Fig. 1A).

We subsequently cloned the two human orthologs of Naked cuticle (hNkd1 and hNkd2) from a human placental cDNA library and generated expression constructs of $h N k d 1$ and $h N k d 2$ fused to a Flag-epitope tag. We found that hNkd1 (Fig. 1B) and hNkd2 (data not shown) share the ability to interact with PR72 in coimmunoprecipitation assays in human embryonic kidney (HEK) 293 cells. No direct interaction was found between PR72 and other components of the Wnt signaling cascade such as dishevelled and GSK3 $\beta$ in coimmunoprecipitation assays (data not shown) and APC in yeast two-hybrid assays (Seeling et al. 1999).

Since PR72 binds to Naked and is a proposed targeting subunit of the PP2A holoenzyme (Hendrix et al. 1993), we asked if PR72 could function as a bridging factor between Naked and the PR65/PP2Ac core dimer. We
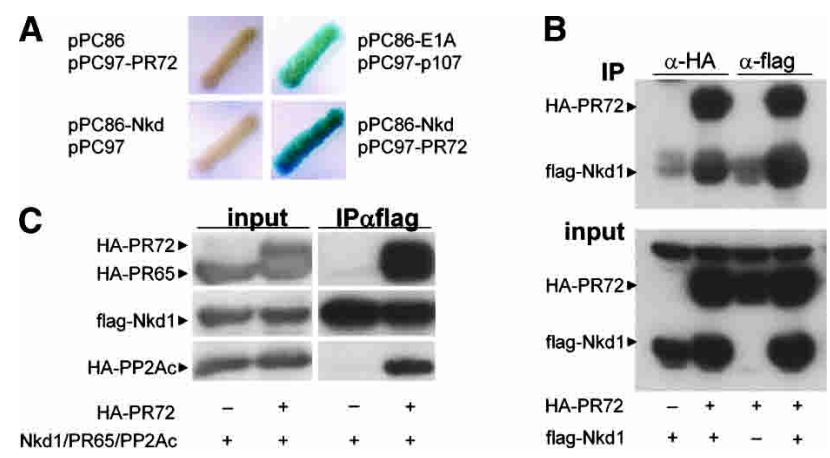

Figure 1. PR72 interacts with Naked cuticle. (A) A yeast two hybrid showing $\beta$-galactosidase staining of yeast colonies containing Gal4-coupled PR72 and transactivation domain (TA)coupled Naked cuticle. (Lower right) Negative controls Gal4PR72 and vector-TA or Gal4-vector and Naked-TA do not stain positive. (Left two panels) The positive control is Gal4-p107 and adenovirus E1A-TA. (B) Immune precipitation of PR72 and Naked cuticle. (Upper right) Extracts from HEK 293 cells ectopically expressing Flag-tagged hNkd1 or HA-tagged hPR72 or both were subjected to immunoprecipitation with anti-Flag and antiHA antibodies as indicated. HA-antibodies did not precipitate Flag-Naked (first lane) and the Flag antibody did not precipitate HA-PR72 (third lane); when coexpressed both were coprecipitated with either anti-HA or ant-Flag (second and fourth lanes). The background in the upper section of the Flag-Naked IP is the Ig heavy chain running at the same height as Flag-Naked. The lower panel shows $10 \%$ of the total lysate used in each of the immunoprecipitations. (C, right two panels) Immune precipitation of Naked cuticle and the PP2Ac/PR65 core dimer in HEK 293 cells in the presence (right) or absence (left) of HA-PR72. The left two panels show $10 \%$ of the total lysate. 
transfected HEK 293 cells with constructs expressing Flag-hNkd1, HA-PR65, and HA-PP2Ac in the presence or absence of HA-PR72 and performed coimmunoprecipitation assays for Flag-Naked cuticle. We found that hNkd1 could form a complex with the PP2A only in the presence of PR72, indicating that PR72 is required as a bridging factor between Naked and the PR65/PP2Ac core dimer (Fig. 1C). These results demonstrate that PR72 can interact with Naked cuticle and facilitates recruitment of the PP2A/PR65 core dimer to the complex.

\section{PR72 is a negative regulator of the classical Wnt signaling pathway}

Since Naked cuticle is an established negative regulator of the canonical Wnt signaling cascade, we addressed the question if PR72 functions as a mediator of the Wnt signaling pathway as well. Figure $2 \mathrm{~A}$ shows that ectopic expression of PR72 represses a Wnt-1-responsive TCF site-containing luciferase reporter construct (Top-Glow) in HEK 293 cells (which respond to Wnt signaling and in which the pathway has a low basal activity) (Jho et al. 2002; Valenta et al. 2003), but not a Fop-Glow reporter containing mutated TCF sites. This repression was seen both in the absence and in the presence of exogenous Wnt1. This suggests that PR72, like Nkd, is a negative regulator of the canonical Wnt signaling cascade. The effect was specific for PR72 since another PP2A B regulatory subunit (PR55 $\gamma$ ) did not show any effect on reporter activity. Both subunits were expressed at similar levels (Fig. 2D). Together, these data suggest that the effects seen here of PR72 expression are specific and not due to titration of other B-subunits from endogenous PP2A complexes that might play a role in this pathway (Seeling et al. 1999; Li et al. 2001; Yang et al. 2003).

Activation of $\beta$-catenin is the most downstream event in the Wnt-signaling cascade. To determine at which level in the Wnt cascade PR72 acts, we used a constitutively active form of $\beta$-catenin, which carries a mutation in the GSK3 $\beta$ phosphorylation sites and is therefore refractory to degradation by the Axin/APC/GSK3 $\beta$ destruction complex. Figure 2B shows that in the presence of this active form of $\beta$-catenin, PR72 is no longer able to inhibit the Top-Glow reporter. This shows that, like Naked cuticle, PR72 antagonizes Wnt signaling upstream of $\beta$-catenin. It was shown in a similar experimental setup that components downstream of $\beta$-catenin can inhibit the activated reporter (Ishitani et al. 1999). This idea was further substantiated by measuring the levels of endogenous $\beta$-catenin in HEK 293 cells following ectopic expression of PR72. We found that endogenous $\beta$-catenin protein levels are significantly reduced in response to PR72 (Fig. 2C). This is in agreement with the conclusion reached above that PR72 inhibits Wnt signaling upstream of $\beta$-catenin. GSK3 $\beta$ is a $\mathrm{LiCl}$-sensitive kinase that is essential for $\beta$-catenin phosphorylation, leading to its destruction by the proteasome in the absence of a Wnt ligand (Ikeda et al. 1998). The PR72-induced reduction in $\beta$-catenin levels was sensitive to $\mathrm{LiCl}$ (Fig. 2C), suggesting that GSK3 $\beta$ activation is required for PR72-
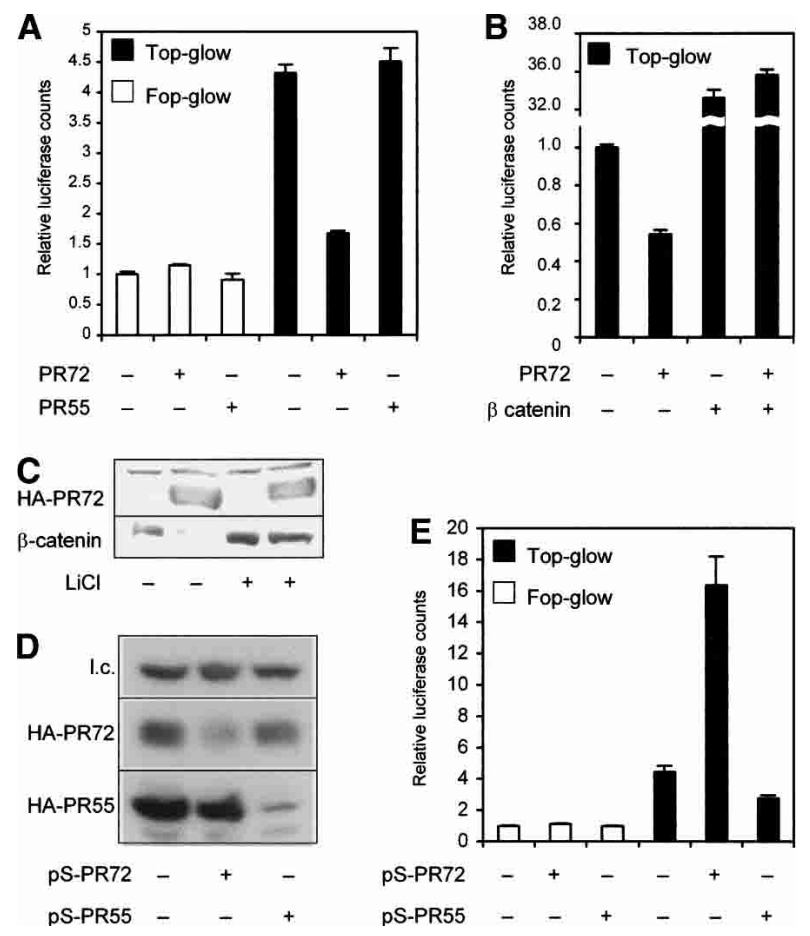

Figure 2. PR72 is a repressor of the canonical Wnt pathway. $(A)$ One-hundred nanograms of TCF containing Top-Glow or FopGlow (containing mutated TCF sites) luciferase reporter, $50 \mathrm{ng}$ of CMV Renilla luciferase, and 5 ng of CMV-Wnt-1 was cotransfected in HEK 293 cells with or without $0.5 \mu \mathrm{g}$ of CMV HA$P R 72$ or CMV HA-PR55 $\gamma$ as indicated. $(B)$ As in $A$, in the presence of either $100 \mathrm{ng}$ of empty vector or phospho-site mutant $\beta$-catenin as indicated. Luciferase activities were determined. (C) Western blot showing lysates of non-Wnt-1-stimulated HEK 293 cells transfected with or without HA-PR72 (lanes 1,2) and repeated after overnight treatment with $10 \mathrm{mM}$ of $\mathrm{LiCl}$ (lanes $3,4)$. Blots were probed with anti-HA (upper panel) or anti- $\beta$ catenin (lower panel). (D) Efficiency of the knock-down constructs was determined by cotransfection of $5 \mu \mathrm{g}$ of the shRNA vectors with a mix of $2 \mu \mathrm{g}$ of CMV HA-PR72, CMV HA-PR55 $\gamma$, and CMV-GFP in a ratio of $1: 1: 1$, one of which was the target for suppression. Forty-eight to seventy-two hours post-transfection, lysates were subjected to Western blot analysis with either anti-HA or anti-Flag and then reprobed with anti-GFP antibodies (1.c.) to determine protein levels. (E) One-hundred nanograms of TCF containing Top-Glow or Fop-Glow (containing mutated TCF sites) luciferase reporter, $50 \mathrm{ng}$ of CMV Renilla luciferase, and $5 \mathrm{ng}$ of CMV-Wnt-1 was cotransfected in HEK 293 cells with $2 \mu \mathrm{g}$ of either an empty pSUPER (pS) or one containing a $P R 72$ targeting shRNA (pS-PR72) or a PR55 targeting shRNA, as indicated.

induced degradation of $\beta$-catenin. It is therefore likely that PR72, like Nkd, uses the canonical Wnt-signaling cascade to regulate cytoplasmic levels of $\beta$-catenin.

Since increasing the levels of PR72 inhibited Wnt signaling, we next asked if reducing the levels of endogenous PR72 could stimulate Wnt signaling. For this purpose, we generated short hairpin RNA (shRNA) expression vectors (Brummelkamp et al. 2002b) specifically targeting $P R 72$ or $P R 55 \gamma$ and tested their ability to inhibit the expression of their cognate targets. We found 
that both constructs were able to effectively reduce protein levels of their corresponding targets when cotransfected into HEK 293 cells (Fig. 2D). When tested for activity on a Top-Glow reporter, we found that knockdown of endogenous PR72, as opposed to ectopic PR72 expression, stimulated the Wnt signaling pathway in HEK 293 cells (Fig. 2E), while no such effect was found for PR55 $\gamma$ knock-down. These results demonstrate that PR72, like Naked cuticle, is a negative regulator of the classical Wnt signaling pathway in cell culture.

\section{Naked cuticle depends on PR72 for its antagonizing function}

We generated shRNA-expressing constructs specific for $h N k d 1$ and $h N k d 2$ and tested their ability to suppress expression of their cognate targets when ectopically coexpressed in tissue culture. We found that both constructs were specific and effective in reducing target protein levels (Fig. 3A). As expected, suppression of endogenous hNkd1 and hNkd2 by shRNA activated Wnt signaling in HEK 293 cells (Fig. 3B). This result is in good agreement with previous results obtained in mouse and fly systems (Zeng et al. 2000; Wharton et al. 2001; Yan et al. 2001a), indicating that Nkd contributes to suppression of the Wnt signal.

When we repeated this experiment in the presence of shRNA vectors targeting PR72 and hNkd for suppression, no super-activation of the Top-Glow reporter was observed (Fig. 3B). This suggests that PR72 and hNkd act in a linear pathway to suppress Wnt signaling.

When hNkd is overexpressed, we observed mild, dosedependent inhibition of the Top-Glow reporter (Fig. 3C). This inhibition is significantly reduced when repeated in the presence of a hairpin vector targeting PR72 for suppression, suggesting that PR72 is required for Nakedmediated repression of the canonical Wnt signaling pathway.

\section{PR72 and Naked regulate dishevelled stability}

Since PR72 recruits PP2A to Naked, we asked whether Naked was a target for dephosphorylation by the PP2A catalytic subunit. We could, however, find no evidence
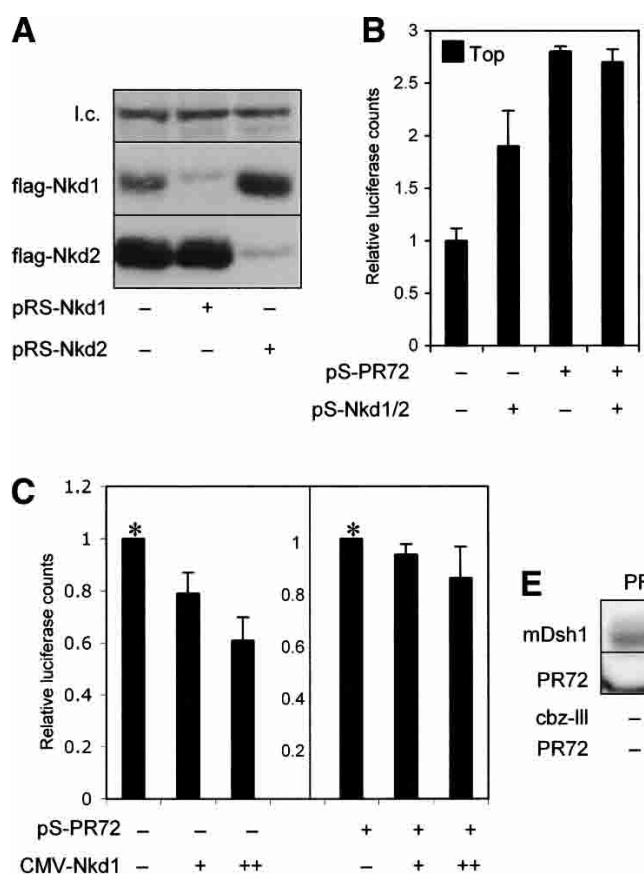
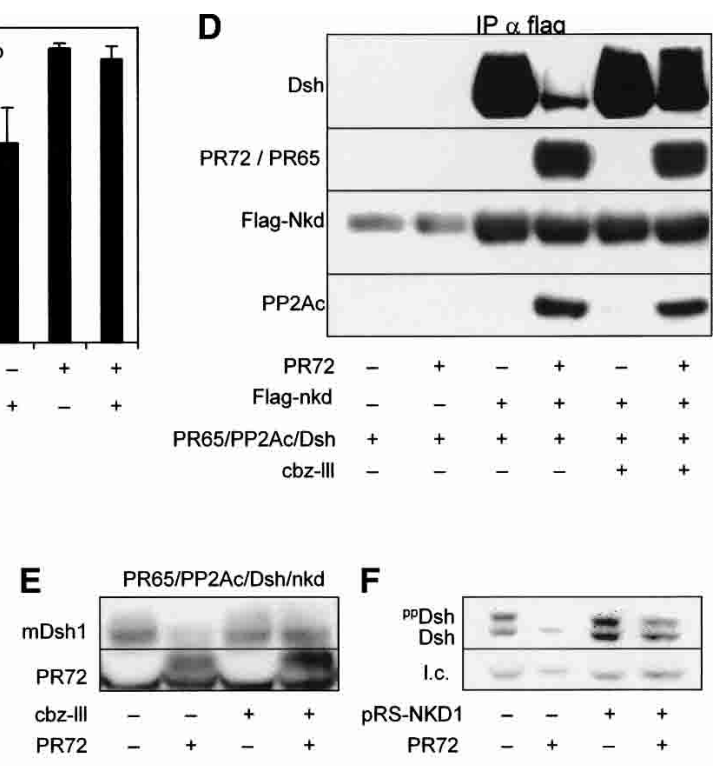

Figure 3. Naked requires PR72 for its function as a Wnt antagonist. (A) Efficiency of knock-down constructs was determined by cotransfection of $5 \mu \mathrm{g}$ of the shRNA vectors with a mix of $2 \mu \mathrm{g}$ of CMV Flag-hNkd1, CMV Flag-hNkd2, or CMV-GFP in a ratio of 1:1:1. Lysates were subjected to Western blot analysis with either anti-HA or anti-Flag and then reprobed with anti-GFP antibodies (1.c.) to determine protein levels. (B) One-hundred nanograms of TCF containing Top-Glow or Fop-Glow (containing mutated TCF sites) luciferase reporter, $50 \mathrm{ng}$ of CMV Renilla luciferase and $5 \mathrm{ng}$ of CMV-Wnt-1 was cotransfected in HEK 293 cells with or without $1 \mu \mathrm{g}$ of pRS-hNkd1 and $1 \mu \mathrm{g}$ of pRS- $h N k d 2$ either in the presence or absence of pS-PR72. $(C)$ In a similar experiment, $0,0.2$, or $0.5 \mu \mathrm{g}$ of CMV-hNkd1 was cotransfected with the Top-Glow reporter in the presence of $2 \mu \mathrm{g}$ of $\mathrm{pS}$ or pS-PR72. (D) Immunoprecipitation for Flag-tagged Naked was done on cell lysates of HEK 293 cells transfected with HA-PR65, HA-PP2Ac, and $m D s h 1$ in the absence or presence of HA-PR72 (every second lane) or Flag-hNkd1 (last four lanes). (E) Cell lysates of HEK 293 cells containing HA-PR72 and mDsh1 with (last two lanes) or without proteasome inhibitors were subjected to Western blot analysis and probed with antibodies targeting dishevelled. PR72 levels were detected using an anti-HA reprobe. (F) Cell lysates of HEK 293 cells containing HA-PR72 with (last two lanes) or without pRs-Nkd1 were subjected to Western blot analysis and probed with antibodies targeting dishevelled. 
to support a role for PR72/PP2A complexes in regulating the phosphorylation of hNkdl using both ${ }^{32} \mathrm{P}$-orthophosphate-labeling experiments and mobility shifts in SDS polyacrylamide gel electrophoresis (data not shown). Alternatively, PR72/PP2A could act on different proteins required for Naked-mediated suppression of Wnt signaling. The only other identified binding partner of Naked cuticle is dishevelled. We therefore asked if the interaction between Naked and dishevelled was affected by PR72. We performed coimmunoprecipitation experiments in HEK 293 cells expressing Flag-Nkd1 and dishevelled in the presence or absence of ectopic PR72. Surprisingly we found that the Naked-dishevelled interaction was lost upon cotransfection of PR72 (Fig. 3D). Since the direct interaction between Naked and dishevelled is likely to be required for Naked inhibitory function, disruption of this complex should then result in an increase in Wnt signaling rather than the negative effect observed for PR72 in our experiments. We therefore wondered if dishevelled-Naked interaction was truly affected or whether the level of dishevelled protein was reduced in the cell. We found that total dishevelled protein levels, both ectopic (Fig. 3E) and endogenous (Fig. $3 \mathrm{~F}$ ), were reduced upon introduction of PR72. Addition of proteasome inhibitors prevented the PR72-induced loss of dishevelled. This was seen both for the total amount of cellular dishevelled (Fig. 3E) and for dishevelled protein in complex with Naked (Fig. 3D). These results suggest that PR72 bound to Naked functions as a regulator of dishevelled protein levels. Analysis of dishevelled phosphorylation status did not reveal a correlation between PR72 expression and dephosphorylation of dishevelled, suggesting that its deregulation by PR72 is likely to be indirect (data not shown).

Loss of Naked by introduction of an shRNA targeting hNkd1 for suppression increased basal dishevelled levels and reduced the negative effects of PR72 on dishevelled stability (Fig. 3F). This result again places PR72 upstream of Naked cuticle and provides evidence that $\mathrm{Na}$ ked, like PR72, is a negative regulator of dishevelled protein levels.

\section{XPR72 is required for gastrulation movements and somite differentiation and development of the eye during Xenopus embryonic development}

To test the biological relevance of our findings, we investigated the role of PR72 during early embryonic development of Xenopus tropicalis, a well-established model for studying Wnt signaling during development. We identified the EST homologous to the 5' amino acid sequence coding for human PR72 from the JGI $X$. tropicalis database (http://www.jgi.doe.gov) and generated oligonucleotides to evaluate expression of XPR72 by RTPCR at different stages of embryonic development. Figure 4A (upper panel) shows that PR72 is maternally expressed and is present during all stages of early embryonic development. Later during development at the tadpole stage we find that $P R 72$ is mainly expressed in somites as judged by whole-mount in situ hybridization
(Fig. 4A, lower panel), which is in concert with results from human tissue blots showing high PR72 RNA in heart and skeletal muscle (Hendrix et al. 1993). Notably, $X n k d$ is also expressed in the somites (data not shown), which could support a possible connection between PR72 and Nkd function in this tissue.

We generated morpholino oligonucleotides ( $\mathrm{MO}$ ) that specifically inhibit translation of RNA from the $X$. tropicalis ortholog of $P R 72$. To restore PR72 RNA in the knock-down embryos, we used human PR72 RNA, which is insensitive to the XPR72 MO due to five mismatches compared to the corresponding Xenopus sequence. We find that depletion of XPR72 with two distinct sets of PR72 MOs causes severe developmental defects, while similar amounts of control MO show no developmental defects. PR72-depleted embryos do not move or swim, which is indicative of differentiation defects of the somites forming the muscle cells. These embryos show a short axis phenotype (Fig. 4B) with a structure reminiscent of an open blastopore caudally (Fig. 4B, arrowheads), which is most likely due to incomplete closure of the blastopore during late gastrulation and indicates an effect on morphogenetic cell movements required for elongation of the body axis. A low frequency of neural tube closure defects (Fig. 4B, arrows) also indicates defects in morphogenetic cell movements during gastrulation. This might link PR72 to dishevelled function in development since defects in morphogenetic cell movements during gastrulation were also described for embryos overexpressing dishevelled (Wallingford et al. 2000). Less expected was the lack of differentiated eyes (Fig. 4C, white arrows). However, ectopic expression of Wnt in the developing anterior neural tissue was previously shown to result in loss of eye formation as shown in the zebrafish Axin1 mutation masterblind (van de Water et al. 2001).

The formation of the somites can be monitored by analyzing the expression of the muscle-specific gene $X m y o D$. Whole-mount in situ hybridization for $X m y o D$ on embryos injected with PR72 MO suggests that the somites were smaller than in control embryos (Fig. 5A). When we injected only one side (either left or right) of the embryos at the four-cell stage, embryos were strongly bent to one side (Fig. 4C). We used the loss of eye formation to identify the side of injection. This demonstrates that the injected side of the embryo /without the eye) was much shorter than the control side, which could indicate a developmental defect of the somites. We could rescue this phenotype for $80 \%$ when we coinjected hPR72 RNA (Fig. 4D), demonstrating that the developmental defects were, indeed, caused by PR72 depletion.

To find evidence for a cooperative function of PR72 with Nkd, we performed double knock-down for PR72 and Nkd with low MO doses, which gave no obvious phenotype when injected alone (data not shown). When we injected the same low amount of PR72 and Nkd MO together, we found embryos with similar phenotypes as we found with higher doses PR72 MO alone (Fig. 5A). This additive effect strongly suggests cooperation between PR72 and Nkd during Xenopus development. 

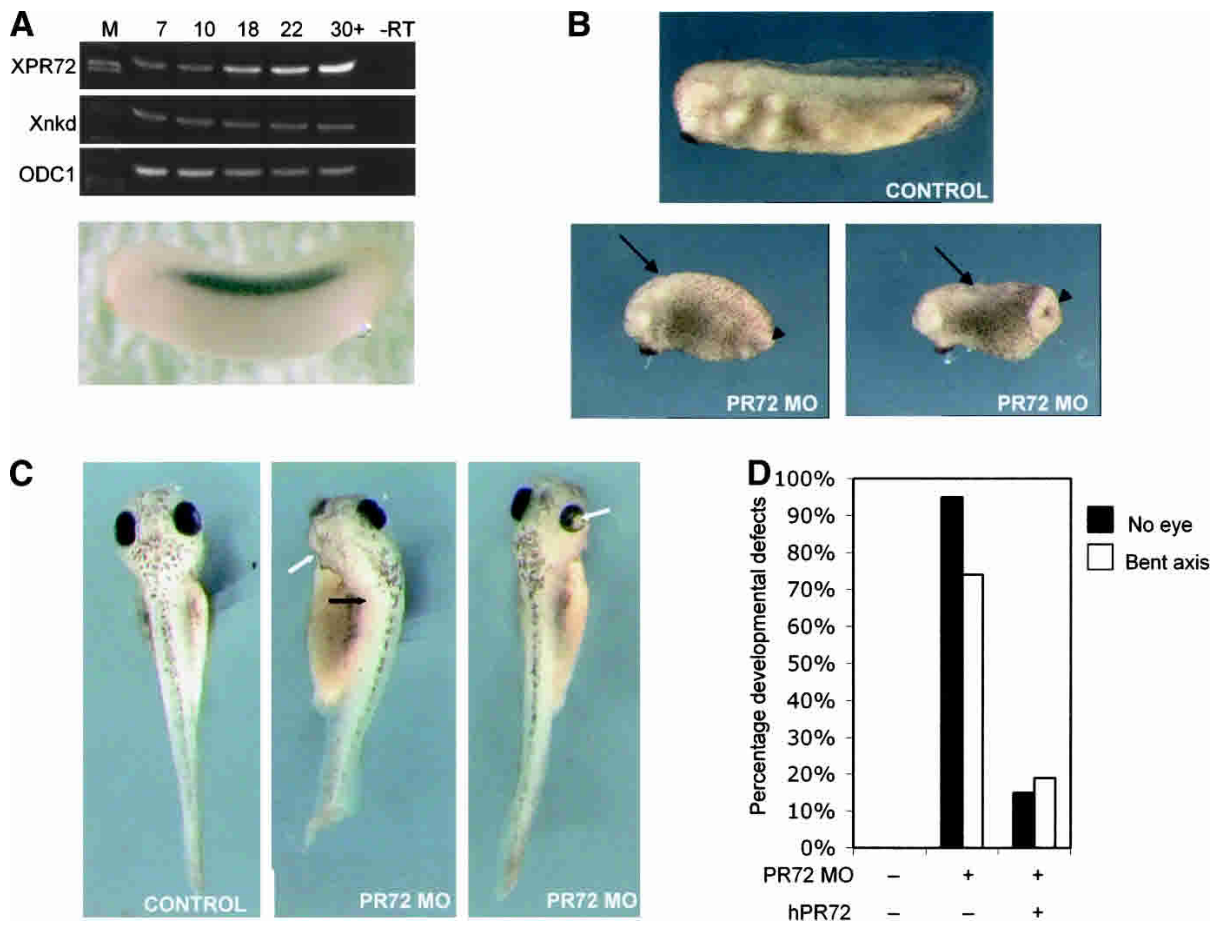

Figure 4. PR72 is required for cell morphogenetic movements during gastrulation. (A) RT-PCR analysis of $X$. tropicalis total RNA from different developmental stages. XPR72 and Xnkd are expressed maternally (stage 7) and throughout early development (stages 10, 18, 22, and 30). (-RT) RT-PCR without reverse transcriptase. ODC1 expression was used as a loading control. (Bottom panel) Whole-mount in situ hybridization for XPR72 in embryos showing predominant staining of somites. $(B)$ Two sets of three nonoverlapping PR72 MOs (1, 4, 5 or 1, 2, 3) both show similar phenotypes (bottom two panels) when injected dorsally at the four-cell stage at equal amounts (10 ng total) compared to control MO-injected (top panel). Phenotypes include defective cell morphogenetic movements during gastrulation, defect in eye development, incomplete neural tube closure (arrows), and incomplete closure of the blastopore during late gastrulation (arrowheads). (C) Injection of PR72 MO in either the left half (middle panel) or right half (right panel) results in a bent axis (black arrow) and underdevelopment of the eye (white arrow) compared to control MO-injected embryos (left panel). (D) Coinjection of $20 \mathrm{pg}$ of human PR72 RNA rescues the developmental defect (graph).

\section{PR72 is required for Naked cuticle to antagonize an ectopic Wnt signal in Xenopus}

To test in a vertebrate model system if PR72 is, indeed, required for the antagonistic function of Nkd in the canonical Wnt signaling pathway, we used the Wnt-induced second axis assay in Xenopus. Using this assay the antagonistic function of Nkd on the canonical Wnt signaling pathway was demonstrated previously by showing that coexpression of Naked rescues the formation of a Wnt-induced secondary body axis (Zeng et al. 2000). We used this assay to investigate the role of PR72 in Nkd-mediated inhibition of Wnt by coinjecting the PR72 MO.

We injected Wnt-1 mRNA in $X$. tropicalis embryos at the ventral side to induce a second body axis (Fig. 5C). This could be rescued by coinjection of $h N k d 1$ RNA (Fig. 5C). However, when we depleted PR72 in the rescue experiment, the ability of hNkdl to inhibit Wnt-induced ectopic body axis formation was strongly reduced (Fig. 5D). This indicates that the antagonizing function of Nkd on the canonical Wnt signaling pathway requires the presence of endogenous XPR72. As a control we replaced PR72 MO with random sequence MO (Genetools, LLC), which did not change the antagonizing effect of
hNkd RNA on the ectopic Wnt signal (data not shown). To demonstrate the specificity of the effect of XPR72 depletion on Nkd function as described above, we restored the level of PR72 by coinjection of human PR72 mRNA, which is insensitive to the PR72 MO. This rescued the antagonizing function of hNkdl on the Wnt signaling pathway (Fig. 5D). These results are consistent with those obtained in cell culture in vitro, and provide evidence that PR72 is required for Naked cuticle to antagonize the canonical Wnt signaling pathway in vertebrates in vivo.

\section{Discussion}

We report here that hPR72, a PP2A B regulatory subunit of previously unknown function, interacts with Naked cuticle, an inhibitor of the canonical Wnt signaling cascade. Naked cuticle was previously identified as an important protein to restrict Wnt signaling in cell culture and during embryonic development (Zeng et al. 2000; Rousset et al. 2001; Yan et al. 2001a). It was subsequently found that Naked cuticle interacts with dishevelled, one of the major orchestrators of the various Wntdriven cascades (Wharton 2003), thereby placing the gene 
A

Figure 5. PR72-depleted embryos show defective somitogenesis and resistance to the effect of hNkdl in a second axis assay. $(A)$ Whole-mount in situ hybridization for somite marker $M y o D$ in embryos injected with control MO (left panel) or equal amounts of PR72 MO (right panel). (B) Whole-mount in situ hybridization for somite marker $M y o D$ in embryos injected with control MO (upper panel) or low amounts of PR72 MO combined with Xnkd MO (lower panel). (C) Wnt-1-induced second axis assay in Xenopus. (Upper panel) Wild-type embryos showing normal embryonic development. (Middle panels) Wnt-1 RNA injection at the ventral side results in embryos with a partial secondary body axis (asterisk). (Bottom panel) The induction of a second axis can be blocked by coinjection of $h N k d$ RNA. ( $D)$ When XPR72 MO was coinjected, hNkd1 lost its ability to antagonize the Wnt signaling pathway. Restoring PR72 levels with $h P R 72$ RNA restored the antagonizing function of hNkdl.
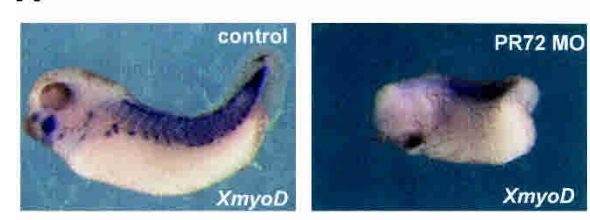

C

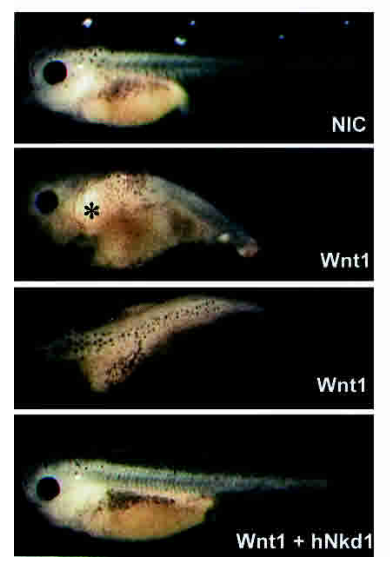

D
B
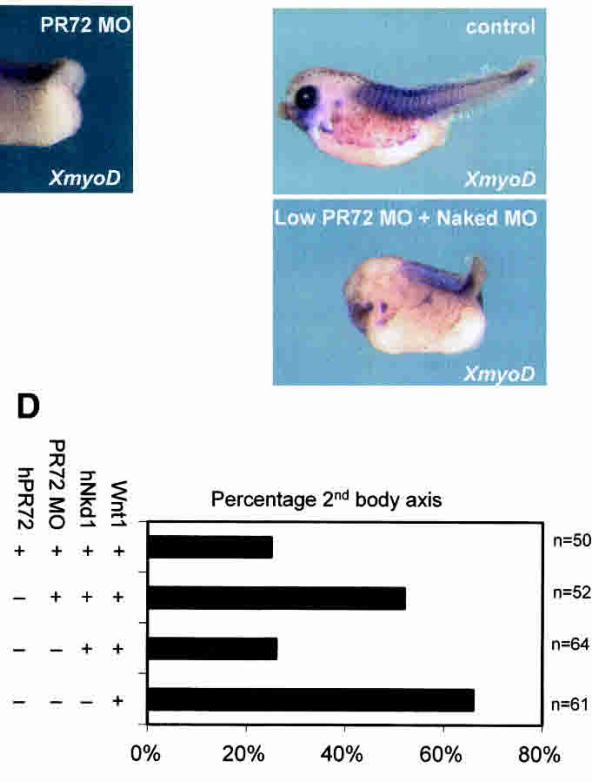

physically in the Wnt signaling cascade, but leaving its molecular regulation illusive. We find that PR72 binds to and is required for the antagonistic effects of $\mathrm{Nkd}$ on Wnt signaling, demonstrating that PR72 is a new modulator of Wnt signaling. PR72, like Nkd, antagonizes the canonical Wnt signal in cell culture. Conversely, loss of PR72, like loss of Nkd, results in activation of the canonical Wnt signaling cascade. Additionally, we found that both PR72 and Naked cuticle are negative regulators of dishevelled protein levels, providing a possible mechanism for their inhibitory actions on the Wnt signaling cascade.

The data obtained in cell culture were confirmed in vivo using the Xenopus second axis assay as a vertebrate model system. We found that XPR72 depletion abolished the inhibitory function of $\mathrm{Nkd}$ on Wnt signaling in Xenopus embryos, demonstrating that $\mathrm{Nkd}$ requires PR72 to modify the canonical Wnt signaling pathway. We subsequently studied the effects of PR72 depletion in untreated Xenopus embryos and found that PR72 is required for morphogenetic cell movements during gastrulation and proper development of the somites and eyes. Gastrulation defects were previously described for Xenopus embryos overexpressing wild-type or a dominant negative form of dishevelled (Wallingford et al. 2000; Yan et al. 2001a), suggesting tight regulation of dishevelled levels is a prerequisite for correct gastrulation movements. Since we find deregulation of dishevelled protein levels in cell culture by PR72, it's possible this effect contributes to the defects observed during development in PR72-depleted Xenopus embryos. Although PR72 RNA is maternally expressed, we did not find evidence that PR72 is required for the cytoplasmic canonical Wnt signal early in development to establish the dorsal-ventral (D/V) body axis. This might not be surprising since maternal Dsh protein is enriched at the dorsal side in an early Xenopus embryo by cortical rotation just after fertilization (Miller et al. 1999b; for review, see Weaver and Kimelman 2004). In agreement with this, Dsh overexpression at the dorsal side was reported not to affect $\mathrm{D} / \mathrm{V}$ axis specification but convergence and extension (Wallingford et al. 2000). The relatively mild gastrulation defects in PR72-depleted embryos compared to the Dsh overexpression phenotype (Wallingford et al. 2000) might also be due to a more modest increase in Dsh levels by PR72 depletion as compared to the levels obtained by ectopic injection of Dsh RNA.

Formation of the somites to divide the vertebrate body axis in segments is established by a process in which blocks bud off from the unsegmented presomitic mesoderm in an anterior to posterior fashion (for review, see Aulehla and Herrmann 2004). The Wnt signaling pathway, among other signaling pathways, plays a role in establishing the dorsal to ventral polarity of the somites (Takada et al. 1994; Fan et al. 1997; Lee et al. 2001) and in regulating the segmentation clock (Aulehla et al. 2003). The self-inhibitory feedback mechanism between Axin2 and the Wnt signal controls the oscillation of Axin2 levels and consequently the rhythmic switching between an active and inactive Wnt signal during elongation of the body axis (Aulehla et al. 2003). This mechanism was shown to contribute to the segmented formation of distinct blocks of somites. Naked and Axin2 are both Wnt-inducible antagonists and are both present in somites (data not shown). This coregulation is also observed in tumors with an activated Wnt signal (Yan et al. 2001b). It is therefore tempting to speculate that both Naked and Axin2 contribute to this segmentation effect during somite development. This could, in turn, account for the somitogenesis defects observed in our PR72/Na- 
ked-depleted embryos. Alternatively, the defects in somitogenesis may be a consequence of the defects observed in cell morphogenetic movements during gastrulation.

The lack of eye development in the PR72 MO-injected embryos resembles the masterblind mutation in zebrafish embryos in which Wnt is ectopically activated due to loss of Axin1 function (van de Water et al. 2001). Similarly to the defects in somitogenesis, one could speculate that repression of the Wnt signal in this context is due to the action of both Naked and Axin, but a definite link between the two remains to be determined. In summary, loss of PR72 in Xenopus embryos results in several developmental defects that are phenotypically similar to those that result from alterations in Wnt signaling. The phenotype caused by depletion of PR72 is different from depletion of another PP2A regulatory subunit, B56e. While B $56 \varepsilon$ is required for specification of the dorsal side during embryogenesis, PR72 is required for correct cell morphogenetic movements during gastrulation and somite development. This underscores the specificity of regulatory subunits of PP2A to correctly modulate different outcomes using the same core unit in different developmental processes.

Our data suggest a role for both PR72 and Naked in negative regulation of dishevelled stability. This would be in agreement with reported similarities between the phenotypes caused by ectopic Naked expression and dishevelled loss-of-function mutants in embryogenesis (Rousset et al. 2001). We find that loss of Naked cooperates with loss of PR72 in disturbing cell morphogenetic movements during gastrulation, which could represent a polarity defect. Since both PR72 and Naked cuticle are negative regulators of dishevelled protein levels, it is difficult to see how either would function as an activator of the PCP pathway as was proposed by Yan et al. (2001a). Indeed, the role of Naked cuticle in PCP is still under debate, since loss of Nkd does not affect cell polarity in the Drosophila wing (Zeng et al. 2000) and Naked misexpression is indistinguishable from dishevelled loss-offunction mutants (Rousset et al. 2001).

It has previously been described that both introducing exogenous dishevelled and interfering with endogenous dishevelled by introduction of a dominant negative mutant can cause defects in cell morphogenetic movements during gastrulation (Wallingford et al. 2000). This result not only underscores the importance of tight regulation of dishevelled levels during development but also makes it difficult to conclude whether the observed defects in gastrulation observed by Yan et al. (2001a) caused by Naked misexpression are the result of an overactive PCP pathway or a defect in this pathway. We propose that PR72 and Naked cuticle are negative regulators of both the canonical and the PCP pathways.

Since PP2A regulatory subunits are generally involved in providing substrate specificity to the holoenzyme (Schonthal 1998; Millward et al. 1999), the most straightforward interpretation of our data is that Naked cuticle is the substrate for the PP2A phosphatase. Support for a role as a PP2A-targeting subunit comes from the finding that the PP2A holoenzyme can form a complex with Naked cuticle in a PR72-dependent manner. However, we did not find an effect of PR72 overexpression or its knock-down on the general phosphorylation status of $\mathrm{Nkd}$ as judged by $\left[{ }^{32} \mathrm{P}\right]$-orthophosphate labeling in HEK 293 cells or alterations in its mobility in SDS-PAGE (data not shown). We cannot exclude that only one of multiple phosphorylation sites on hNkd is regulated by PR72, which would be masked in an assay addressing overall phosphorylation status of hNkd. It is, however, very well possible that other, yet unidentified, proteins interact with Nkd that are targets of the PR72/PP2A holoenzyme. If this is the case, Naked cuticle would act as a docking platform that, like dishevelled, brings together multiple proteins involved in the regulation of the different signals through the Wnt cascade (Wharton 2003). It is possible that dishevelled is a direct target for PR72/ PP2A complexes. This could be suggested by the finding that PR72 reduces the levels of phosphorylated Dsh (Fig. 3 F). However, we cannot exclude that phosphorylated Dsh is more rapidly degraded, explaining its lower abundance. Furthermore, we found no direct evidence supporting dishevelled dephosphorylation (data not shown) prior to its destruction, suggesting regulation of dishevelled by PR72 is likely to be indirect.

Notably, PR72 and Nkd share EFX calcium-binding domains generally believed to be involved in protein folding. It is tempting to speculate on a role for the Wnt/ $\mathrm{Ca}^{2+}$ pathway in the regulation of these two proteins and their interaction. This would further integrate the Wnt/ $\mathrm{Ca}^{2+}$ and PCP pathways and also connect to the classical Wnt signaling cascade. It was previously described for PR72 that the two EFX domains, indeed, play a role in protein folding upon binding of $\mathrm{Ca}^{2+}$ (Janssens et al. 2003).

The regulation of Naked cuticle function by PR72 reported here adds a new level of complexity into this illusive antagonist of the canonical Wnt signaling cascade. Correct regulation of this inhibitory response is equally important as positive regulation of the Wnt signal itself, both fine-tuned to orchestrate the extent of the Wnt signal during embryonic development. Conversely, alterations in PR72-dependent signaling might contribute to deregulated Wnt signaling during tumor progression. Indeed, earlier work indicates that PR72 is a negative regulator of cell cycle progression (Janssens et al. 2003). However, it is not clear if this negative effect on cell cycle results from inhibition of Wnt signaling. Consistent with a role for PR72 in oncogenesis is also the finding that binding of PR72 to the PP2A core complex is deregulated in colorectal cancer (Wang et al. 1998; Ruediger et al. 2001). Notably some $80 \%$ of human colon cancers arise from deregulated canonical Wnt signaling (Polakis 2000; Giles et al. 2003). Although no causal relation between deregulation of PR72 and tumor formation has been made, its role in regulating cell cycle and its deregulation in colon tumors provide tempting speculation. Future experiments will have to establish the molecular relation between Naked cuticle, PR72, and regulation of dishevelled and will perhaps bring more insight 
into the mechanism of Wnt signal restriction during embryonic development and oncogenesis.

\section{Materials and methods}

\section{Yeast two-hybrid screen}

Yeast strain Y190 (Harper et al. 1993) containing "bait" plasmid pPC97-PR72 encoding the GAL4 DNA-binding domain (DBD) fused to full-length $h P R 72$ was transformed with a day 14.5 CD1 mouse embryo library (Chevray and Nathans 1992) by the lithium acetate method (Schiestl and Gietz 1989). Transformants were selected for growth on plates lacking histidine and supplemented with $25 \mathrm{mM} 3$-aminotriazole. $\mathrm{His}^{+}$colonies were subsequently analyzed for $\beta$-galactosidase activity as previously described (Durfee et al. 1993). cDNA plasmids derived from double-positive yeast colonies were tested for bait specificity by retransformation with pPC97 lacking an insert.

\section{Cell lines, transfections, and luciferase assays}

293 HEK cells were cultured in Dulbecco's modified Eagle's medium supplemented with $10 \%$ fetal calf serum, L-glutamine, and penicillin/streptomycin (GIBCO). Transient transfections in these cells were performed by the calcium phosphate precipitation method (van der Eb and Graham 1980). Luciferase assays were performed using the Dual luciferase system (Promega). One-hundred nanograms of Top-Glow or Fop-Glow luciferase vector was transfected in the presence of $5 \mathrm{ng}$ of CMV-Wnt1 and $20 \mathrm{ng}$ of CMV-Renilla. For loss-of-function assays, $2 \mu \mathrm{g}$ of either pSUPER or pRETRO-SUPER (Brummelkamp et al. 2002a) was cotransfected, and luciferase counts were measured $60 \mathrm{~h}$ posttransfection using a TD-20/20 Luminocounter (Promega). For gain-of-function assays, $500 \mathrm{ng}$ of CMV construct was cotransfected, and luciferase counts were measured $24 \mathrm{~h}$ post-transfection.

\section{Plasmids and reagents}

Anti-Flag (m2) was purchased from Sigma; anti-HA (Y11), antiGFP (FL), anti- $\beta$-catenin (H-102), and anti-Dsh1 (3F12) antibodies were purchased from Santa Cruz. PPC97-PR72 was generated by cloning $P R 72$ as a SalI digest from pCMV-PR72 (Voorhoeve et al. 1999) into the SalI site of pPC97 in frame with the Gal4-DBD. Human Nkd1 and Nkd2 were PCR-amplified from a human placental cDNA library (Clonetech) and cloned as BamHI/EcoRV fragments in frame into a Flag-tag containing (pVLAG) pcDNA3.1-hygro vector (Invitrogen). CMV-HA-PP2Ac and CMV-HA-PR65 were described before (Voorhoeve et al. 1999).

Top-Glow and Fop-Glow reporter constructs were a gift from Hans Clevers (Hubrecht Laboratory, Utrecht, The Netherlands), pRK5-SK- $\beta$-catenin and pRK5-SK- $\beta$-catenin $\Delta$ GSK were obtained from Roel Nusse (Department of Developmental Biology, Beckman Center, Howard Hughes Medical Institute, Stanford University, Stanford, CA). PR55y was PCR-amplified from a whole-brain cDNA library (Clonetech) and BamHI/XbaI-cloned into pMV in frame with the HA-tag and subsequently Xhol/ NotI-cloned into pcDNA3.1-neo. Nineteen-mer hairpin oligonucleotides for PR55y (CATGGAGGCAAGACCCATAG), $h P R 72$ (GGGACCCGGATTTAAGGGG), hNKD1 (CATCGAG AGGAGAAACCAC), and $h N k d 2$ (CCAC TCCTCGGGCAG CAGC) were cloned into pSUPER or pRETRO-SUPER as described before (Brummelkamp et al. 2002b). Morpholino antisense oligonucleotides targeting XPR72 (MO-1, TCAGCGAA
GTCTCСTTTATCATCAT; MO-2, CAG AAATGGAAGAAT GTAGCAGCCA; MO-3, AGAGTCAAGTGTATGAGATGGT ACC; MO-4, CTGGGCAACCTCTGGATTCAGAAAT; MO-5, AAGAATGTAGCAGCCAAAGGAGAGT) and Xnkd (AAA GATTCCCAAAGGCAGAACATCA) were bought from Gene Tools. For the T7T6-hNKD1 expression construct, $h N k d 1$ was cut as a Bam/EcoRV fragment from pVLAG-hNkd1, blunted with Klenow enzyme and cloned into the EcoRV site of T7T6 vector in between the $5^{\prime}$ - and $3^{\prime}-\beta$-globin UTR.

\section{Immunoblotting and coimmunoprecipitation experiments}

Cells were lysed in $0.5 \mathrm{~mL}$ of NETN lysis buffer $(100 \mathrm{mM} \mathrm{NaCl}$, $1 \mathrm{mM}$ EDTA, $20 \mathrm{mM}$ Tris at $\mathrm{pH} 8.0,0.5 \%$ NP-40) containing complete protease inhibitor cocktail (Roche), $10 \mathrm{mM} \mathrm{NaF}$, and $10 \mathrm{mM} \beta$-glycerolphosphate, and complexes were immunoprecipitated with $2 \mu \mathrm{g}$ of the indicated antibody, pre-conjugated protein G Sepharose beads. Bound proteins were eluted by boiling in SDS-sample buffer and resolved by SDS-PAGE.

Western blots were performed using whole cell extracts, separated on $6 \%-10 \%$ SDS-PAGE gels, and transferred to polyvinylidine difluoride membranes (Millipore).

\section{RNA isolation from Xenopus embryos and RT-PCR}

Total RNA from $X$. tropicalis embryos at different developmental stages was isolated using Tripure reagent (Roche), according to the manufacturer's protocol $(400 \mu \mathrm{L}$ of Tripure was used per 10 embryos). cDNA was obtained by reverse transcriptase using Superscript II (Invitrogen). The primers used for PCR were XPR72 fwd, 5'-GATAAAGGAGACTTCGCTGAGG; XPR72 rev, 5'-TTAGCCCCTCCTCCAACTCTG; Xnkd fwd, 5'-GAT TGTACCGTGTCTCTGATG; Xnkd rev, 5'-CAATGTGAAG GTCCATTCTTGC; ODC1 fwd，5'-CTGTGGTGTTGAGAA GATG. Amplified PCR fragments were analyzed by sequencing.

\section{Whole-mount in situ hybridizations}

Whole-mount ISH was performed as described in Molenaar et al. (1998) with modifications for X. tropicalis: hybridization at $65^{\circ} \mathrm{C}$ without RNase treatment. DNA plasmids were linearized and used as template for DIG-labeled antisense RNA synthesis (Roche). RNA probes were purified using RNeasy columns (QIAGEN). XMyoD X. tropicalis-specific probes were constructed by RT-PCR using primer sequences designed from the $X$. tropicalis EST database (Sanger Center).

mRNA and morpholino oligo injections in Xenopus tropicalis

Plasmid DNA of T7Ts-XWnt-1 (Noordermeer et al. 1989), T7Ts$h N k d$, and T7Ts-hPR72 were linearized and used as template for synthesis of capped mRNA using Message Machine (Ambion). Capped mRNA was purified using RNeasy columns (QIAGEN). X. tropicalis embryos were obtained by in vivo fertilization and raised in a standard amphibian saline solution ( $12 \%$ modified Marc's Ringer, MMR) at $23^{\circ} \mathrm{C}$. Embryos were injected at the four-cell stage in the two ventral blastomeres with 0.5 pg of Wnt-1 RNA alone, with 0.5 pg of Wnt-1 RNA together with $9 \mathrm{pg}$ of $h N k d$ RNA and $10 \mathrm{ng}$ of control morpholino (Genetools), with 0.5 pg of Wnt-1 RNA, 9 pg of Nkd RNA, and $10 \mathrm{ng}$ of PR72 morpholino oligo (Genetools), or with $0.5 \mathrm{pg}$ of Wnt-1 RNA, 8 pg of Nkd RNA, 10 ng of PR72 morpholino oligo, and 10 pg of $h P R 72$ RNA. Dorsal injection was done with $10 \mathrm{ng}$ of mixed nonoverlapping XPR72 MOs $(1,4$, and 5 or 1, 2, and 3) to maximize knock-down efficiency or $10 \mathrm{ng}$ of control MO. After injection, embryos were kept for $6 \mathrm{~h}$ in $12 \% \mathrm{MMR}$ with addition of $3 \%$ Ficoll (Amersham Biosciences) at $23^{\circ} \mathrm{C}$ and subsequently raised in $12 \% \mathrm{MMR}$ at $23^{\circ} \mathrm{C}$. At tailbud stage the 
embryos were fixed in MEMPFA (100 mM MOPS [Sigma] at $\mathrm{pH}$ 7.4; 2 mM EGTA [Sigma]; $1 \mathrm{mM} \mathrm{MgSO}_{4}$ [Merck]; 4\% paraformaldehyde [Sigma]) and analyzed for the formation of a secondary axis. Embryos were staged according to Nieuwkoop and Faber (1967).

\section{Acknowledgments}

We thank Hans Clevers and Roel Nusse for plasmids and Brian Hemmings for antisera against PR72. This work was supported by a grant from the Dutch Cancer Society (KWF) and the European Union Grant QLRT-2000-01275 (G.R.).

\section{References}

Aberle, H., Bauer, A., Stappert, J., Kispert, A., and Kemler, R. 1997. $\beta$-Catenin is a target for the ubiquitin-proteasome pathway. EMBO I. 16: 3797-3804.

Agathon, A., Thisse, C., and Thisse, B. 2003. The molecular nature of the zebrafish tail organizer. Nature 424: 448-452.

Aulehla, A. and Herrmann, B.G. 2004. Segmentation in vertebrates: Clock and gradient finally joined. Genes \& Dev. 18: 2060-2067.

Aulehla, A., Wehrle, C., Brand-Saberi, B., Kemler, R., Gossler, A., Kanzler, B., and Herrmann, B.G. 2003. Wnt3a plays a major role in the segmentation clock controlling somitogenesis. Dev. Cell 4: 395-406.

Axelrod, J.D., Miller, J.R., Shulman, J.M., Moon, R.T., and Perrimon, N. 1998. Differential recruitment of Dishevelled provides signaling specificity in the planar cell polarity and Wingless signaling pathways. Genes \& Dev. 12: 2610-2622.

Boutros, M. and Mlodzik, M. 1999. Dishevelled: At the crossroads of divergent intracellular signaling pathways. Mech. Dev. 83: 27-37.

Boutros, M., Paricio, N., Strutt, D.I., and Mlodzik, M. 1998. Dishevelled activates JNK and discriminates between JNK pathways in planar polarity and wingless signaling. Cell 94: $109-118$.

Bouwmeester, T. 2001. The Spemann-Mangold organizer: The control of fate specification and morphogenetic rearrangements during gastrulation in Xenopus. Int. J. Dev. Biol. 45: 251-258.

Brummelkamp, T.R., Bernards, R., and Agami, R. 2002a. Stable suppression of tumorigenicity by virus-mediated RNA interference. Cancer Cell 2: 243-247.

. 2002b. A system for stable expression of short interfering RNAs in mammalian cells. Science 296: 550-553.

Brunner, E., Peter, O., Schweizer, L., and Basler, K. 1997. pangolin encodes a Lef- 1 homologue that acts downstream of Armadillo to transduce the Wingless signal in Drosophila. $\mathrm{Na}$ ture 385: 829-833.

Cadigan, K.M. and Nusse, R. 1997. Wnt signaling: A common theme in animal development. Genes \& Dev. 11: 3286-3305.

Chevray, P.M. and Nathans, D. 1992. Protein interaction cloning in yeast: Identification of mammalian proteins that react with the leucine zipper of Jun. Proc. Natl. Acad. Sci. 89: 5789-5793.

Durfee, T., Becherer, K., Chen, P.L., Yeh, S.H., Yang, Y., Kilburn, A.E., Lee, W.H., and Elledge, S.J. 1993. The retinoblastoma protein associates with the protein phosphatase type 1 catalytic subunit. Genes \& Dev. 7: 555-569.

Fan, C.M., Lee, C.S., and Tessier-Lavigne, M. 1997. A role for WNT proteins in induction of dermomyotome. Dev. Biol. 191: 160-165.
Giles, R.H., van Es, J.H., and Clevers, H. 2003. Caught up in a Wnt storm: Wnt signaling in cancer. Biochim. Biophys. Acta 1653: $1-24$.

Habas, R., Dawid, I.B., and He, X. 2003. Coactivation of Rac and Rho by Wnt/Frizzled signaling is required for vertebrate gastrulation. Genes \& Dev. 17: 295-309.

Harper, J.W., Adami, G.R., Wei, N., Keyomarsi, K., and Elledge, S.J. 1993. The p21 Cdk-interacting protein Cip1 is a potent inhibitor of G1 cyclin-dependent kinases. Cell 75: 805-816.

Hendrix, P., Mayer-Jackel, R.E., Cron, P., Goris, J., Hofsteenge, J., Merlevede, W., and Hemmings, B.A. 1993. Structure and expression of a $72-\mathrm{kDa}$ regulatory subunit of protein phosphatase 2A. Evidence for different size forms produced by alternative splicing. J. Biol. Chem. 268: 15267-15276.

Ikeda, S., Kishida, S., Yamamoto, H., Murai, H., Koyama, S., and Kikuchi, A. 1998. Axin, a negative regulator of the Wnt signaling pathway, forms a complex with GSK-3 $\beta$ and $\beta$-catenin and promotes GSK-3 $\beta$-dependent phosphorylation of $\beta$-catenin. EMBO I. 17: 1371-1384.

Ishitani, T., Ninomiya-Tsuji, J., Nagai, S., Nishita, M., Meneghini, M., Barker, N., Waterman, M., Bowerman, B., Clevers, H., Shibuya, H., et al. 1999. The TAK1-NLK-MAPKrelated pathway antagonizes signalling between $\beta$-catenin and transcription factor TCF. Nature 399: 798-802.

Janssens, V., Jordens, J., Stevens, I., Van Hoof, C., Martens, E., De Smedt, H., Engelborghs, Y., Waelkens, E., and Goris, J. 2003. Identification and functional analysis of two $\mathrm{Ca}^{2+}$. binding EF-hand motifs in the B"/PR72 subunit of protein phosphatase 2A. J. Biol. Chem. 278: 10697-10706.

Jho, E.H., Zhang, T., Domon, C., Joo, C.K., Freund, J.N., and Costantini, F. 2002. Wnt $/ \beta$-catenin/Tcf signaling induces the transcription of Axin2, a negative regulator of the signaling pathway. Mol. Cell. Biol. 22: 1172-1183.

Keller, R. 2002. Shaping the vertebrate body plan by polarized embryonic cell movements. Science 298: 1950-1954.

Kishida, S., Yamamoto, H., Hino, S., Ikeda, S., Kishida, M., and Kikuchi, A. 1999. DIX domains of Dvl and axin are necessary for protein interactions and their ability to regulate $\beta$-catenin stability. Mol. Cell. Biol. 19: 4414-4422.

Klingensmith, J., Nusse, R., and Perrimon, N. 1994. The Drosophila segment polarity gene dishevelled encodes a novel protein required for response to the wingless signal. Genes \& Dev. 8: 118-130.

Kuhl, M., Sheldahl, L.C., Park, M., Miller, J.R., and Moon, R.T. 2000. The Wnt/Ca ${ }^{2+}$ pathway: A new vertebrate Wnt signaling pathway takes shape. Trends Genet. 16: 279-283.

Lee, C.S., Buttitta, L., and Fan, C.M. 2001. Evidence that the WNT-inducible growth arrest-specific gene 1 encodes an antagonist of Sonic hedgehog signaling in the somite. Proc. Nat1. Acad. Sci. 98: 11347-11352.

Li, X., Yost, H.J., Virshup, D.M., and Seeling, J.M. 2001. Protein phosphatase 2A and its B56 regulatory subunit inhibit Wnt signaling in Xenopus. EMBO J. 20: 4122-4131.

Lustig, B., Jerchow, B., Sachs, M., Weiler, S., Pietsch, T., Karsten, U., van de Wetering, M., Clevers, H., Schlag, P.M., Birchmeier, W., et al. 2002. Negative feedback loop of Wnt signaling through upregulation of conductin/axin2 in colorectal and liver tumors. Mol. Cell. Biol. 22: 1184-1193.

Mao, J., Wang, J., Liu, B., Pan, W., Farr III, G.H., Flynn, C., Yuan, H., Takada, S., Kimelman, D., Li, L., et al. 2001. Low-density lipoprotein receptor-related protein-5 binds to Axin and regulates the canonical Wnt signaling pathway. Mol. Cell 7: 801-809.

Miller, J.R., Hocking, A.M., Brown, J.D., and Moon, R.T. 1999a. Mechanism and function of signal transduction by the Wnt $/ \beta$ catenin and Wnt/Ca ${ }^{2+}$ pathways. Oncogene 18: 7860-7872. 
Miller, J.R., Rowning, B.A., Larabell, C.A., Yang-Snyder, J.A., Bates, R.L., and Moon, R.T. 1999b. Establishment of the dorsal-ventral axis in Xenopus embryos coincides with the dorsal enrichment of dishevelled that is dependent on cortical rotation. J. Cell Biol. 146: 427-437.

Millward, T.A., Zolnierowicz, S., and Hemmings, B.A. 1999. Regulation of protein kinase cascades by protein phosphatase 2A. Trends Biochem. Sci. 24: 186-191.

Molenaar, M., Roose, J., Peterson, J., Venanzi, S., Clevers, H., and Destree, O. 1998. Differential expression of the HMG box transcription factors XTcf-3 and XLef-1 during early Xenopus development. Mech. Dev. 75: 151-154.

Moon, R.T. and Kimelman, D. 1998. From cortical rotation to organizer gene expression: Toward a molecular explanation of axis specification in Xenopus. Bioessays 20: 536-545.

Niehrs, C. 1999. Head in the WNT: The molecular nature of Spemann's head organizer. Trends Genet. 15: 314-319.

Nieuwkoop, P.D. and Faber, J. 1967. Normal table of Xenopus laevis (Daudin), 2nd ed. North-Holland Publishing Co., Amsterdam, The Netherlands.

Noordermeer, J., Meijlink, F., Verrijzer, P., Rijsewijk, F., and Destree, O. 1989. Isolation of the Xenopus homolog of int$1 /$ wingless and expression during neurula stages of early development. Nucleic Acids Res. 17: 11-18.

Perrimon, N. and McMahon, A.P. 1999. Negative feedback mechanisms and their roles during pattern formation. Cell 97: $13-16$.

Polakis, P. 2000. Wnt signaling and cancer. Genes \& Dev. 14: $1837-1851$.

Rousset, R., Mack, J.A., Wharton Jr., K.A., Axelrod, J.D., Cadigan, K.M., Fish, M.P., Nusse, R., and Scott, M.P. 2001. Naked cuticle targets dishevelled to antagonize Wnt signal transduction. Genes \& Dev. 15: 658-671.

Rousset, R., Wharton Jr., K.A., Zimmermann, G., and Scott, M.P. 2002. Zinc-dependent interaction between dishevelled and the Drosophila Wnt antagonist naked cuticle. J. Biol. Chem. 277: 49019-49026.

Ruediger, R., Pham, H.T., and Walter, G. 2001. Alterations in protein phosphatase $2 \mathrm{~A}$ subunit interaction in human carcinomas of the lung and colon with mutations in the $A \beta$ subunit gene. Oncogene 20: 1892-1899.

Schiestl, R.H. and Gietz, R.D. 1989. High efficiency transformation of intact yeast cells using single stranded nucleic acids as a carrier. Curr. Genet. 16: 339-346.

Schonthal, A.H. 1998. Role of PP2A in intracellular signal transduction pathways. Front. Biosci. 3: D1262-D1273.

Seeling, J.M., Miller, J.R., Gil, R., Moon, R.T., White, R., and Virshup, D.M. 1999. Regulation of $\beta$-catenin signaling by the B56 subunit of protein phosphatase 2A. Science 283: 20892091.

Sheldahl, L.C., Slusarski, D.C., Pandur, P., Miller, J.R., Kuhl, M., and Moon, R.T. 2003. Dishevelled activates $\mathrm{Ca}^{2+}$ flux, PKC, and CamKII in vertebrate embryos. J. Cell Biol. 161: 769-777.

Shulman, J.M., Perrimon, N., and Axelrod, J.D. 1998. Frizzled signaling and the developmental control of cell polarity. Trends Genet. 14: 452-458.

Smit, L., Baas, A., Kuipers, J., Korswagen, H., van de Wetering, M., and Clevers, H. 2004. Wnt activates the Tak1/Nemolike kinase pathway. J. Biol. Chem. 279: 17232-17240.

Takada, S., Stark, K.L., Shea, M.J., Vassileva, G., McMahon, J.A., and McMahon, A.P. 1994. Wnt-3a regulates somite and tailbud formation in the mouse embryo. Genes \& Dev. 8: $174-189$.

Theisen, H., Purcell, J., Bennett, M., Kansagara, D., Syed, A., and
Marsh, J.L. 1994. dishevelled is required during wingless signaling to establish both cell polarity and cell identity. Development 120: 347-360.

Valenta, T., Lukas, J., and Korinek, V. 2003. HMG box transcription factor TCF-4's interaction with CtBP1 controls the expression of the Wnt target Axin2/Conductin in human embryonic kidney cells. Nucleic Acids Res. 31: 2369-2380.

van der Eb, A.J. and Graham, F.L. 1980. Assay of transforming activity of tumor virus DNA. Methods Enzymol. 65: 826839.

van de Water, S., van de Wetering, M., Joore, J., Esseling, J., Bink, R., Clevers, H., and Zivkovic, D. 2001. Ectopic Wnt signal determines the eyeless phenotype of zebrafish masterblind mutant. Development 128: 3877-3888.

van de Wetering, M., Cavallo, R., Dooijes, D., van Beest, M., van Es, J., Loureiro, J., Ypma, A., Hursh, D., Jones, T., Bejsovec, A., et al. 1997. Armadillo coactivates transcription driven by the product of the Drosophila segment polarity gene dTCF. Cell 88: 789-799.

Voorhoeve, P.M., Hijmans, E.M., and Bernards, R. 1999. Functional interaction between a novel protein phosphatase $2 \mathrm{~A}$ regulatory subunit, PR59, and the retinoblastoma-related p107 protein. Oncogene 18: 515-524.

Wallingford, J.B., Rowning, B.A., Vogeli, K.M., Rothbacher, U., Fraser, S.E., and Harland, R.M. 2000. Dishevelled controls cell polarity during Xenopus gastrulation. Nature 405: 8185.

Wang, S.S., Esplin, E.D., Li, J.L., Huang, L., Gazdar, A., Minna, J., and Evans, G.A. 1998. Alterations of the PPP2R1B gene in human lung and colon cancer. Science 282: 284-287.

Weaver, C. and Kimelman, D. 2004. Move it or lose it: Axis specification in Xenopus. Development 131: 3491-3499.

Wharton Jr., K.A. 2003. Runnin' with the Dvl: Proteins that associate with Dsh/Dvl and their significance to Wnt signal transduction. Dev. Biol. 253: 1-17.

Wharton Jr., K.A., Zimmermann, G., Rousset, R., and Scott, M.P. 2001. Vertebrate proteins related to Drosophila Naked cuticle bind Dishevelled and antagonize Wnt signaling. Dev. Biol. 234: 93-106.

Yan, D., Wallingford, J.B., Sun, T.Q., Nelson, A.M., Sakanaka, C., Reinhard, C., Harland, R.M., Fantl, W.J., and Williams, L.T. 2001a. Cell autonomous regulation of multiple Dishevelled-dependent pathways by mammalian Nkd. Proc. Natl. Acad. Sci. 98: 3802-3807.

Yan, D., Wiesmann, M., Rohan, M., Chan, V., Jefferson, A.B., Guo, L., Sakamoto, D., Caothien, R.H., Fuller, J.H., Reinhard, C., et al. 2001b. Elevated expression of axin2 and hnkd mRNA provides evidence that $\mathrm{Wnt} / \beta$-catenin signaling is activated in human colon tumors. Proc. Natl. Acad. Sci. 98: 14973-14978.

Yang, J., Wu, J., Tan, C., and Klein, P.S. 2003. PP2A:B56e is required for $\mathrm{Wnt} / \beta$-catenin signaling during embryonic development. Development 130: 5569-5578.

Yost, C., Torres, M., Miller, J.R., Huang, E., Kimelman, D., and Moon, R.T. 1996. The axis-inducing activity, stability, and subcellular distribution of $\beta$-catenin is regulated in Xenopus embryos by glycogen synthase kinase 3. Genes \& Dev. 10: $1443-1454$.

Zeng, W., Wharton Jr., K.A., Mack, J.A., Wang, K., Gadbaw, M., Suyama, K., Klein, P.S., and Scott, M.P. 2000. naked cuticle encodes an inducible antagonist of Wnt signalling. Nature 403: 789-795. 


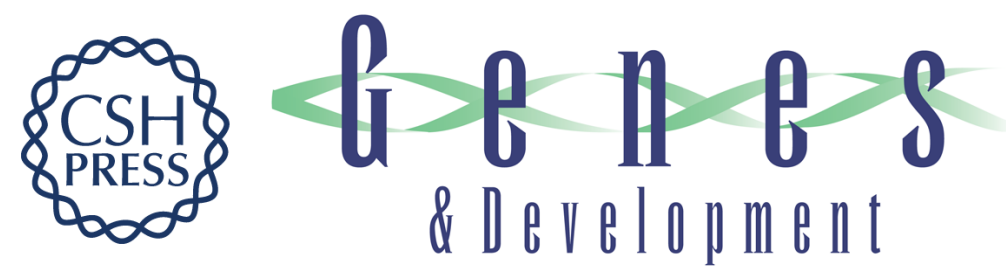

\section{PR72, a novel regulator of Wnt signaling required for Naked cuticle function}

Menno P. Creyghton, Giulietta Roël, Pieter J.A. Eichhorn, et al.

Genes Dev. 2005, 19:

Access the most recent version at doi:10.1101/gad.328905

References This article cites 63 articles, 26 of which can be accessed free at: http://genesdev.cshlp.org/content/19/3/376.full.htmI\#ref-list-1

License

Email Alerting

Receive free email alerts when new articles cite this article - sign up in the box at the top Service right corner of the article or click here.

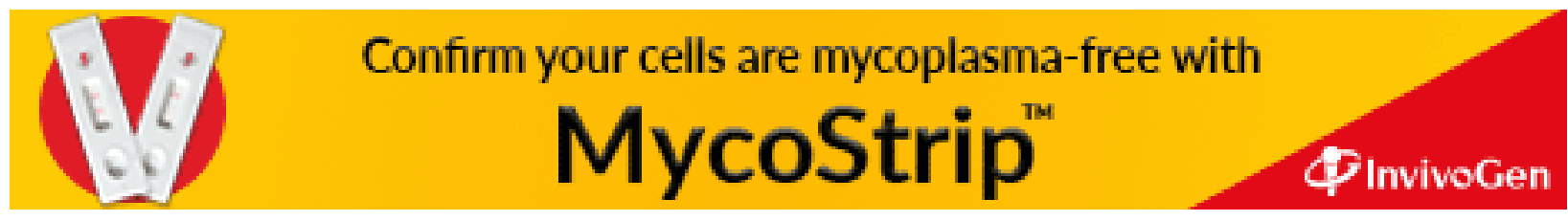

